\title{
Variability of marine aerosol fine-mode fraction and estimates of anthropogenic aerosol component over cloud-free oceans from the Moderate Resolution Imaging Spectroradiometer (MODIS)
}

Article

Published Version

Yu, H., Chin, M., Remer, L. A., Kleidman, R. G., Bellouin, N., Bian, H. and Diehl, T. (2009) Variability of marine aerosol finemode fraction and estimates of anthropogenic aerosol component over cloud-free oceans from the Moderate Resolution Imaging Spectroradiometer (MODIS). Journal of Geophysical Research - Atmospheres, 114 (D10). ISSN 01480227 doi: https://doi.org/10.1029/2008JD010648 Available at https://centaur.reading.ac.uk/34635/

It is advisable to refer to the publisher's version if you intend to cite from the work. See Guidance on citing.

Published version at: http://dx.doi.org/10.1029/2008JD010648

To link to this article DOI: http://dx.doi.org/10.1029/2008JD010648

Publisher: American Geophysical Union

All outputs in CentAUR are protected by Intellectual Property Rights law, including copyright law. Copyright and IPR is retained by the creators or other copyright holders. Terms and conditions for use of this material are defined in 
the End User Agreement.

www.reading.ac.uk/centaur

\section{CentAUR}

Central Archive at the University of Reading

Reading's research outputs online 


\title{
Variability of marine aerosol fine-mode fraction and estimates of anthropogenic aerosol component over cloud-free oceans from the Moderate Resolution Imaging Spectroradiometer (MODIS)
}

\author{
Hongbin Yu, ${ }^{1,2}$ Mian Chin, ${ }^{2}$ Lorraine A. Remer, ${ }^{2}$ Richard G. Kleidman, ${ }^{2,3}$ \\ Nicolas Bellouin, ${ }^{4}$ Huisheng Bian, ${ }^{1,2}$ and Thomas Diehl ${ }^{1,2}$ \\ Received 24 June 2008; revised 24 March 2009; accepted 30 March 2009; published 29 May 2009.
}

[1] In this study, we examine seasonal and geographical variability of marine aerosol fine-mode fraction $\left(f_{m}\right)$ and its impacts on deriving the anthropogenic component of aerosol optical depth $\left(\tau_{a}\right)$ and direct radiative forcing from multispectral satellite measurements. A proxy of $f_{m}$, empirically derived from the Moderate Resolution Imaging Spectroradiometer (MODIS) Collection 5 data, shows large seasonal and geographical variations that are consistent with the Goddard Chemistry Aerosol Radiation Transport (GOCART) and Global Modeling Initiative (GMI) model simulations. The so-derived seasonally and spatially varying $f_{m}$ is then implemented into a method of estimating $\tau_{a}$ and direct radiative forcing from the MODIS measurements. It is found that the use of a constant value for $f_{m}$ as in previous studies would have overestimated $\tau_{a}$ by about $20 \%$ over global ocean, with the overestimation up to $\sim 45 \%$ in some regions and seasons. The 7-year (2001-2007) global ocean average $\tau_{a}$ is 0.035 , with yearly average ranging from 0.031 to 0.039 . Future improvement in measurements is needed to better separate anthropogenic aerosol from natural ones and to narrow down the wide range of aerosol direct radiative forcing.

Citation: Yu, H., M. Chin, L. A. Remer, R. G. Kleidman, N. Bellouin, H. Bian, and T. Diehl (2009), Variability of marine aerosol fine-mode fraction and estimates of anthropogenic aerosol component over cloud-free oceans from the Moderate Resolution Imaging Spectroradiometer (MODIS), J. Geophys. Res., 114, D10206, doi:10.1029/2008JD010648.

\section{Introduction}

[2] With the implementation of multiwavelength, multiangle, and polarization measuring capabilities, current satellite measurements can be used to categorize aerosol types in terms of microphysical properties, such as particle size and shape [e.g., Kahn et al., 2001; Tanré et al., 2001; Higurashi and Nakajima, 2002; Winker et al., 2007]. For example, the fine-mode fraction, a measure of the contribution of finemode aerosols to the aerosol optical depth (AOD or $\tau$ ), has been obtained from enhanced satellite sensors (e.g., the Moderate resolution Imaging Spectroradiometer (MODIS)) with improved data quality [Tanré et al., 1997; Remer et al., 2005]. Given that anthropogenic aerosols are predominately fine-mode or in the submicron range, the fine-mode fraction in conjunction with the total aerosol optical depth can be used as a tool for separating anthropogenic aerosol from dust [Kaufman et al., 2002]. Kaufman et al. [2005a, 2005b]

\footnotetext{
${ }^{1}$ Goddard Earth Science and Technology Center, University of Maryland at Baltimore County, Baltimore, Maryland, USA.

${ }^{2}$ Laboratory for Atmospheres, NASA Goddard Space Flight Center, Greenbelt, Maryland, USA.

${ }^{3}$ Science System and Applications, Inc., Lanham, Maryland, USA.

${ }^{4}$ Met Office, Exeter, UK.
}

Copyright 2009 by the American Geophysical Union. 0148-0227/09/2008JD010648 further developed a quantitative method that uses MODIS over-ocean retrievals in a consistent way to estimate the anthropogenic component (e.g., originating from industrial and urban pollution and biomass burning smoke) of aerosol optical depth, $\tau_{a}$, as follows:

$$
\tau_{a}=\left[\left(f-f_{d}\right) \tau-\left(f_{m}-f_{d}\right) \tau_{m}\right] /\left(f_{a}-f_{d}\right),
$$

where $\tau$ and $f$ respectively represents total aerosol optical depth and fine-mode fraction retrieved directly from MODIS, both at $550 \mathrm{~nm}$. Subscripts $a, d$, and $m$ denote anthropogenic, dust, and marine aerosol components, respectively. Marine aerosol optical depth $\tau_{m}$ is empirically determined to be a constant of 0.06 [Kaufman et al., 2005a] or a function of near-surface wind speed [Kaufman et al., 2005b]. The finemode fractions for marine $\left(f_{m}\right)$, anthropogenic $\left(f_{a}\right)$, and dust $\left(f_{d}\right)$ aerosol were assumed to be constant, which were then derived from Terra MODIS Collection 4 measurements in selected regions where the specific aerosol type predominates and contributions of background aerosol are empirically accounted for [Kaufman et al., 2005a]. Clearly this algorithm does not assume that all fine-mode AOD comes from anthropogenic contribution or anthropogenic AOD is exclusively fine-mode. Contributions from natural aerosols (dust and marine aerosol) to fine-mode AOD are empirically accounted for. The essence of this algorithm is that the 
MODIS data are used in a consistent way. The MODIS finemode fractions could be different from ground-truth values as a result of retrieval uncertainties [Anderson et al., 2005a; Kleidman et al., 2005]. However, by using the fine-mode fractions $\left(f, f_{m}, f_{a}\right.$, and $\left.f_{d}\right)$ consistently from MODIS, one should be able to separate the components of $\tau_{a}$ and $\tau_{d}$ better than if using inconsistent values of fine-mode fraction from other sources. Parallel to Kaufman et al. [2005a, 2005b], Bellouin et al. [2005] developed a method that uses measurement-based fine-mode fraction thresholds for anthropogenic aerosol and sea salt aided by satelliteobserved absorbing aerosol index to separate anthropogenic aerosol from dust and sea salt.

[3] These satellite-based approaches have since inspired the community to further explore the use of satellites to quantify aerosol direct radiative forcing by anthropogenic aerosol [e.g., Anderson et al., 2005b, Christopher et al., 2006; Yu et al., 2006] and to estimate trans-boundary transport of pollution aerosol [Rudich et al., 2008; Yu et al., 2008]. This approach, along with improvements in data sets from ground-based network and field campaigns [Bates et al., 2006; Yu et al., 2006, and references therein] and dedicated and coordinated efforts on aerosol modeling [Schulz et al., 2006], has contributed to the reduced uncertainty of both the aerosol direct radiative forcing and total anthropogenic radiative forcing as assessed in the Intergovernmental Panel on Climate Change (IPCC) Fourth Assessment Report [Haywood and Schulz, 2007].

[4] Significant endeavors are needed to further investigate this approach and explore the use of satellite measurements for a better understanding of anthropogenic aerosol radiative forcing. For example, the inherent assumptions in deriving equation (1) need to be assessed and improved. In this study, we examine the assumption of constant fine-mode fraction for marine aerosol $\left(f_{m}\right)$ and propose a self-consistent approach to improve the characterization of seasonal and spatial variations of $f_{m}$. Over remote oceans, aerosols are generated from bursting bubbles that inject sea salt particles, dimethylsulfide (DMS) and organic matters into the marine boundary layer. The DMS oxidation produces $\mathrm{SO}_{2}$ and sulfates. The organic particles and DMS-oxidized sulfates contribute to the optical depth predominantly in the submicron range. The sea salt aerosols have much broader size distributions, with mass concentrated in the supermicron size range. The submicron sea salt is, however, much more efficient in scattering the solar radiation. As a result, the submicron sea salt constitutes a significant contributor to the sea salt optical depth and also an important component of fine-mode marine aerosol optical depth [Bates et al., 2001]. The amount, composition, and size of marine-generated aerosols should depend on a variety of atmospheric and oceanic parameters, such as biological activities of ocean, sea-surface temperature, ocean upwelling, near-surface wind speed, atmospheric oxidizing capacity, among others [O'Dowd et al., 2004; Leck and Bigg, 2005]. This complexity would result in large seasonal and geographical variations of $f_{m}$, as can be inferred from some observations [e.g., Wilson and Forgan, 2002; Shinozuka et al., 2004].

[5] In section 2, we derive $f_{m}$ from the Terra MODIS Collection 5 (C5) data and discuss its seasonal and geographical variations in conjunction with the Goddard Chemistry Aerosol Radiation Transport (GOCART) and Global
Modeling Initiative (GMI) model simulations of marine aerosol. The derived marine fine-mode fraction, which is seasonally and geographically varying, is then utilized to derive the anthropogenic aerosol optical depth from 2001 to 2007 MODIS observations. Section 3 examines the seasonal and interannual variability of $\tau_{a}$ and its comparisons with model simulation and previous studies. Major results and conclusions are summarized in section 4.

\section{Marine Aerosol Fine-Mode Fraction From MODIS: Seasonal and Geographical Variations}

[6] MODIS C5 aerosol retrievals with consistent algorithms have recently become available [Remer et al., 2006, 2008; Levy et al., 2007]. Because values of the aerosol finemode fraction are sensitive to details of the algorithm and MODIS calibration, it warrants a reassessment of the finemode fractions for anthropogenic, dust, and marine aerosol in order to apply the method of Kaufman et al. [2005a, 2005b] to MODIS C5. Jones and Christopher [2007], hereafter referred to as $\mathrm{JC} 07$, derived the fine-mode fraction values for anthropogenic, dust, and sea salt aerosol from 1-year Terra MODIS C5 data, with aerosol type characterization guided by GOCART model simulations. Here we follow the method as described by Kaufman et al. [2005a, 2005b] by selecting the representative regions and seasons dominated by pollution (i.e., North Atlantic off the coast of New England in summer), dust (i.e., North Atlantic off the coast of North Africa in summer), and marine aerosol (i.e., south to Australia) to the Terra MODIS C5 Level 3 daily data (at a resolution of $1^{\circ} \times 1^{\circ}$ ) from 2001 to 2007 . When deriving fine-mode fractions for dust and pollution, a contribution by marine aerosol is empirically excluded [Kaufman et al., 2005a]. Table 1 lists the newly derived representative values of fine-mode fraction for individual aerosol types and their comparisons with those derived from Terra MODIS Collection 4 (C4) data [Kaufman et al., 2005a, $2005 \mathrm{~b}$. The fine-mode fraction for mineral dust as derived from $\mathrm{C} 5$ is smaller than that from $\mathrm{C} 4$, while that for marine aerosol shows the opposite relationship. For pollution aerosol, the fine-mode fraction is similar between $\mathrm{C} 5$ and $\mathrm{C} 4$. These differences result from assumptions about the optical properties of coarse-mode particles that were adjusted to better match more recent observations in C5 algorithm [Remer et al., 2008]. The consequence of this algorithm change is to reduce the positive bias in the fine-mode fraction retrieved by C4 [Kleidman et al., 2005; Remer et al., 2008].

[7] Our derived fine-mode fractions values are different from those derived by JC07. JC07 derived fine-mode fraction is $0.83,0.44$, and 0.25 for anthropogenic, dust, and sea salt aerosol, respectively. Differences between this study and that of JC07 could have resulted from several possible factors. First, JC07 derived these values over much broader areas than this study does and the differences between the two studies may have come from spatial variability of particle size for a specific aerosol type. It is also possible that MODIS and GOCART differ in the characterization of aerosol types. Second, while JC07 used monthly MODIS C5 data, we are using MODIS C5 daily $1^{\circ} \times 1^{\circ}$ data in this study. Third, it is expected that the fine-mode fraction for sea salt of JC07 is smaller than the derived value for marine aerosol in this study 
Table 1. Comparisons of the Fine-Mode Fractions at $550 \mathrm{~nm}$ for Individual Aerosol Types Derived From Terra MODIS Collections 4 and 5

\begin{tabular}{lcc}
\hline Aerosol Types & Collection 5 & Collection 4 \\
\hline Pollution & 0.90 & 0.92 \\
Mineral dust & 0.37 & 0.51 \\
Marine aerosol & 0.45 & 0.32 \\
\hline
\end{tabular}

because of the exclusion of contribution of submicron sulfate produced from DMS by JC07. Note also that the sea salt finemode fraction from JC07 may be biased low because of cloud contamination [Zhang et al., 2005] and unaccounted-for whitecaps over the "roaring forties." Fourth, contribution of background marine aerosol was accounted for in this study but not accounted for by JC07 when deriving the fine-mode fractions for anthropogenic aerosol and dust. This difference may partly explain larger fine-mode fraction for anthropogenic aerosol derived in this study.

[8] By applying equation (1) with these new values of $f_{m}, f_{d}$, and $f_{a}$ (in Table 1) to the MODIS C5 data, we obtain the global ocean average anthropogenic AOD of 0.040 , which is about $20 \%$ larger than the average $(0.033)$ or is at the upper bound (with an estimated uncertainty of $30 \%$ ) as derived from MODIS C4 [Kaufman et al., 2005a]. This is opposite to the study by Bellouin et al. [2008] that show a $25 \%$ decrease of anthropogenic AOD over ocean when updating from $\mathrm{C} 4$ to $\mathrm{C} 5$. Since the same thresholds of the fine-mode fraction were used to separate aerosol types for both C5 and C4 in Bellouin et al. [2005, 2008], the reduced fine-mode fraction over oceans in C5 [Remer et al., 2008] results in the smaller anthropogenic AOD derived from C5 [Bellouin et al., 2008] than that from C4 [Bellouin et al., 2005].

[9] As discussed earlier, marine aerosol fine-mode fraction should present large spatial and seasonal variations and a use of constant $f_{m}$ could introduce large errors to the derived anthropogenic aerosol optical depth and direct radiative forcing. Here we derive the climatology of seasonal average fine-mode fraction for background marine aerosol by averaging 2001-2007 Terra/MODIS daily fine-mode fraction weighted by $\tau$ for $0.03<\tau<0.10$ in individual $1^{\circ} \times 1^{\circ}$ grids. We assume that $f_{m}$ has relatively small inter-annual variability and the multiyear data are then used to obtain a better spatial coverage. It is also required that the number of available daily measurements in each $1^{\circ} \times 1^{\circ}$ grid box during a season is no less than 10 for calculating a seasonal average. The lower bound of $\tau$ is set to exclude data with relatively large uncertainties, while the upper bound of $\tau$ is chosen for a compromise of excluding continental influences but acquiring adequate spatial coverage. Note that $\tau<0.03$ accounts for $\sim 10 \%$ of all over-ocean data [Remer et al., 2008]. Spatial gaps in the derived $f_{m}$ shrink or expand respectively with increasing or decreasing the upper bound of $\tau$ near coasts of major continental aerosol source regions. For the selected $\tau$ range, continental influences are likely to exist. However, such residual continental influence appears to have a small effect on the derived $f_{m}$. As shown in Figure 1, for example, by varying the upper bound of $\tau$ from 0.1 to 0.15 , the difference of the derived $f_{m}$ in individual grids is predominantly $(\sim 98.5 \%)$ within \pm 0.1 , in which $\sim 80 \%$ is within \pm 0.05 .
[10] Kaufman et al. [2001] derived the climatology of optical depth and properties of the baseline marine aerosol from multiyear measurements of nine Aerosol Robotic Network (AERONET) stations. The $f_{m}$ at $500 \mathrm{~nm}$ is about 0.64 over the Atlantic (averaged over five stations) and 0.56 over the Pacific (averaged over four stations) [Kaufman et al., 2001, Table 2]. By extracting values from the derived $f_{m}$ climatology in this study for those stations, we get $f_{m}$ at $550 \mathrm{~nm}$ of $0.58 \pm 0.11$ over the Atlantic and $0.54 \pm 0.05$ over the Pacific, which is in good agreement with that of Kaufman et al. [2001]. Given the difficulty in obtaining spatial and temporal variations of the fine-mode fraction of marine aerosol from other measurements, we examine simulations of two global chemical transport models in this study, namely GOCART and GMI. To model marine aerosol, we only consider emissions of sea salt and DMS from ocean and volcanic $\mathrm{SO}_{2}$. The sulfate produced from DMS and volcanic emissions and sub-micron sea salt are categorized into "fine mode" in calculating the fine-mode fraction for the marine aerosol. GOCART takes into account both eruptive and noneruptive volcanic sources [Chin et al., 2000a, 2002], whereas GMI only includes noneruptive volcanoes. Processes represented in the models are chemistry, convection, advection, boundary layer mixing, dry and wet deposition, gravitational settling, and hygroscopic growth of aerosol particles. Despite being driven by same meteorological and photochemical fields, the two models differ in the oceanic DMS and volcanic $\mathrm{SO}_{2}$ emissions, and parameterizations of several processes that determine aerosol such as aqueous phase reactions, dry and wet deposition, gravitational settling, and convective transport [Chin et al., 2000a, 2000b, 2002; Bian et al., 2009]. Thus the simulated marine fine-mode fraction can still be different between the two models.

[11] Figure 2 shows the MODIS-derived $f_{m}$ and its comparisons with GOCART and GMI simulations. Differences of $0.1-0.2$ exist between the MODIS-based $f_{m}$ and model simulations in some regions, which however would generally fall within the uncertainty ranges of either method. All three sets of $f_{m}$ show generally consistent, pronounced seasonal and geographical variations. The marine fine-mode fraction is larger in summer than in winter, and also larger in tropical and coastal regions than in high latitudes and remote oceans. These seasonal and spatial variations result

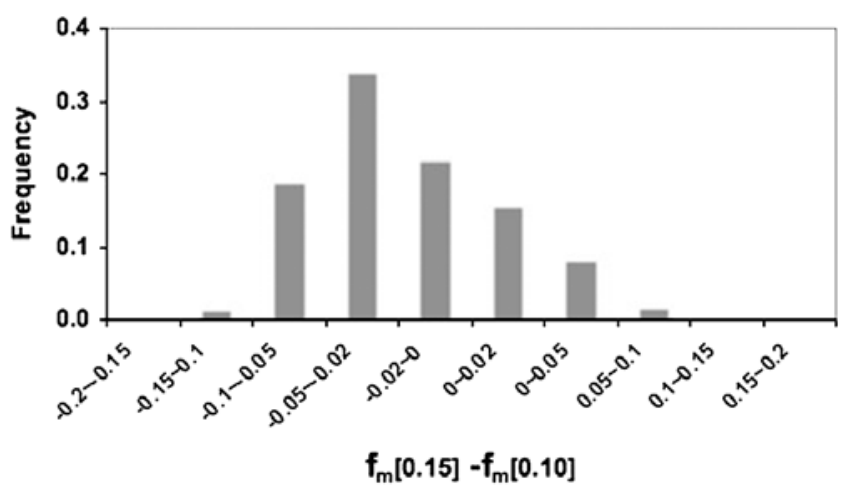

Figure 1. Frequency distribution of the $f_{m}$ difference between using AOD at $550 \mathrm{~nm}$ of 0.15 and 0.10 as the upper bound in deriving the marine aerosol fine-mode fraction. 


\section{DJF}

(a) MODIS

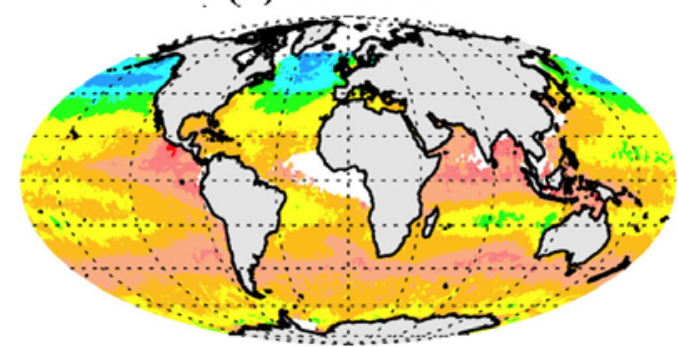

(c) GOCART

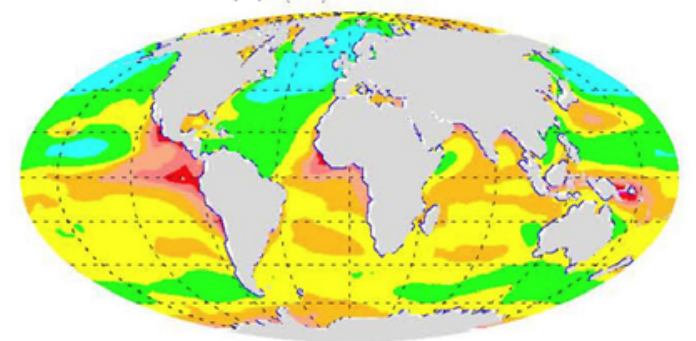

(e) GMI
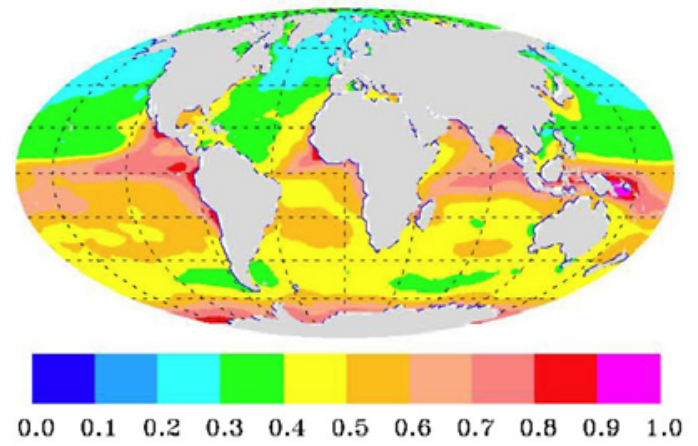

JJA (b) MODIS

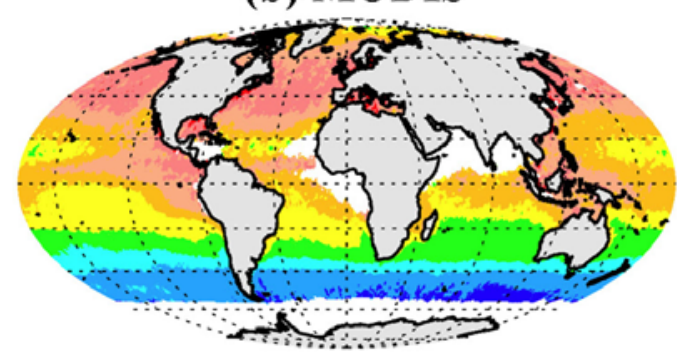

(d) GOCART

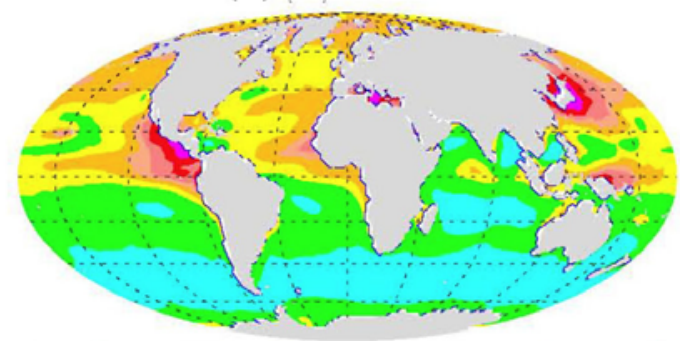

(f) GMI

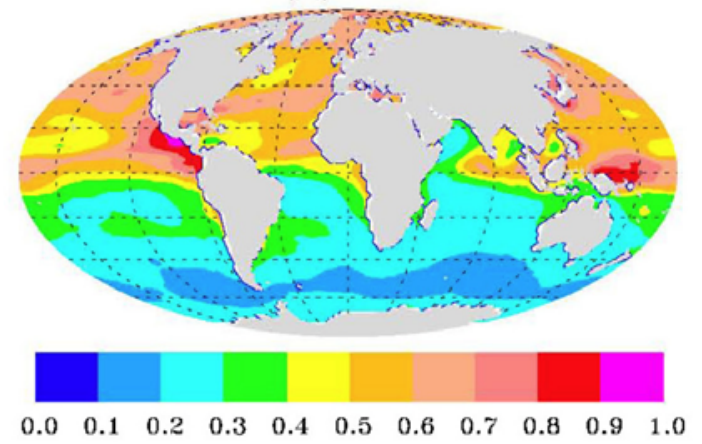

Figure 2. Distributions of marine aerosol fine-mode fraction $\left(f_{m}\right)$ at $550 \mathrm{~nm}$ for (left) DecemberJanuary-February (DJF) and (right) June-July-August (JJA) as (a and b) derived from 2001 to 2007 Terra/ MODIS Collection 5 Level 3 daily $1^{\circ} \times 1^{\circ}$ data and simulated by (c and d) GOCART and (e and f) GMI model. For these GOCART and GMI simulations, size-segregated sea salt and sulfates produced from ocean dimethylsulfide (DMS) and volcanic $\mathrm{SO}_{2}$ are considered to represent the marine aerosol. Sulfate is assumed to be exclusively fine-mode.

from a complicated interplay of several ocean and atmospheric processes that determine the loading of sea salt and marine sulfate. Sea salt particles are generated via the bubble-bursting process, with a higher production rate primarily associated with strong wind speed [e.g., Shinozuka et al., 2004]. Factors that determine the sulfate loading are associated with ocean DMS production, emission of DMS to the marine boundary layer, and chemical transformation of DMS to $\mathrm{SO}_{2}$ and sulfate. The in-water DMS production is highly correlated with the intensity of phytoplankton activities that depends on ocean upwelling, availability of iron, among others [e.g., Liss, 2007]. Since DMS is saturated in most surface ocean waters, the DMS flux to the atmosphere is determined by the air-sea transfer rate depending on seawater DMS concentrations, near-surface wind speed, and atmospheric stability. In the atmosphere, DMS is transformed to $\mathrm{SO}_{2}$ and sulfate through oxidation by the $\mathrm{OH}$ radical (day) and $\mathrm{NO}_{3}$ (night), with a rate depending on the atmospheric oxidizing capacity that is stronger in summer and in the tropics.

\section{Updated Estimates of Anthropogenic Aerosol Optical Depth}

[12] The large spatial and temporal variations of $f_{m}$ suggest that a use of constant $f_{m}$ could introduce large uncertainties in the derived $\tau_{a}$ and direct radiative forcing, depending on season and region. Here we use the MODIS-based climatology of seasonal average $f_{m}$ shown in Figure 2 and $f_{a}$ and $f_{d}$ from Table 1 to derive the anthropogenic aerosol optical depth from Terra/MODIS Collection 5. Spatial gaps in MODIS $f_{m}$ as shown in Figure 2 (excluding gaps in high latitudes where MODIS aerosol retrievals are not available and hence anthropogenic aerosol optical depth cannot be derived) are filled with GOCART simulations by simply scaling the GOCART simulation of $f_{m}$ with the average 

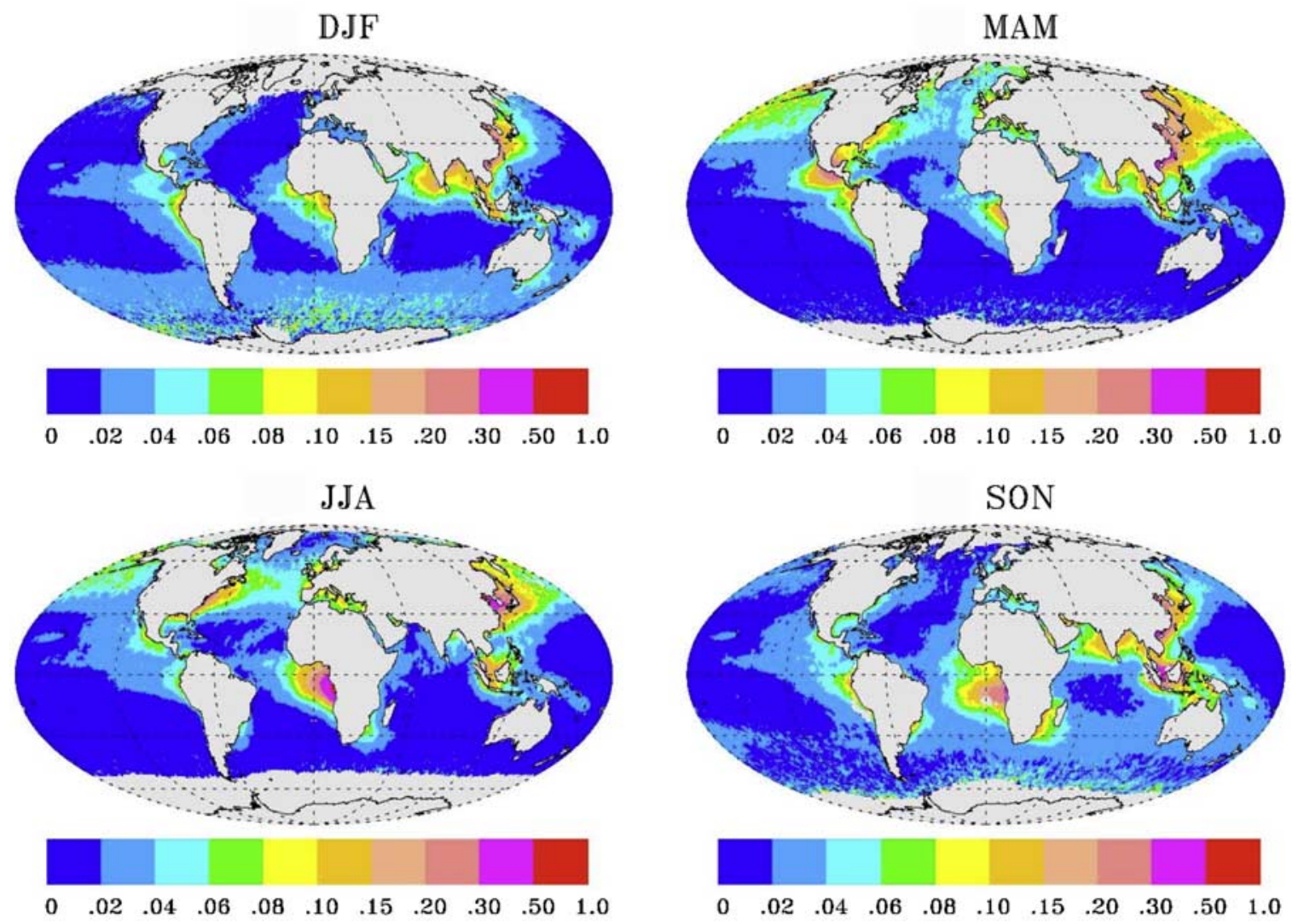

Figure 3a. Seven-year (2001-2007) climatology of seasonal average anthropogenic aerosol optical depth at $550 \mathrm{~nm}$, derived from Terra/MODIS Collection 5 data by using the MODIS-based seasonally and spatially varying marine fine-mode fraction $\left(f_{m}\right)$ as shown in Figure 2.

MODIS/GOCART ratio in selected regions surrounding the data gaps. Using GOCART to fill in gaps for MODIS does introduce additional uncertainty to the final estimates. However, it is still a "reasonable" step to take in order to obtain a global picture because on an annual average, the modelassisted piece accounts for only about $5 \%$ of the oceans. Other assumptions are the same as those of Kaufman et al. [2005a].

[13] Figure 3a shows distributions of seasonal average $\tau_{a}$ over 2001-2007 data period. Evident from Figure 3a are several pronounced continental outflows from major industrial pollution and biomass burning regions. For example, pollution and biomass burning aerosols from Asia and Europe sweep across the North Pacific basin during the boreal spring and summer. Tropical biomass burning smoke is transported to surrounding oceans during the austral winter (JJA) and spring (SON). North American pollution is transported to Europe in summer. Pollution from the Indian subcontinent spreads to the northern Indian Ocean in premonsoon season. Central America fires contribute aerosols to the eastern tropical Pacific. High values of $\tau_{a}$ over the Southern Ocean are most likely artifacts because of large uncertainties of MODIS retrievals in the region [Zhang et al., 2005; Smirnov et al., 2006]. The 7-year global (excluding some high latitudes where data are not available) ocean average $\tau_{a}$ is 0.035 , with annual average ranging from 0.031 to 0.039 . Seasonal averages of anthropogenic AOD, along with those for fine-mode fraction and anthropogenic fraction (a ratio of $\tau_{a}$ to $\tau$ ), were calculated over ocean in 13 zones [following $Y u$ et al., 2006], as shown in Figure 3b.

[14] Figure 4 compares the derived anthropogenic AOD using spatially and seasonally varying $f_{m}$ (Figures $2 \mathrm{a}$ and b) against that using a constant $f_{m}(0.45)$ from Table 1 for the same MODIS Terra C5 data. Each of 52 data points represents a seasonal average in each of the 13 zones defined in Figure 3b. Only in a few regions during some seasons does the use of constant $f_{m}$ yields $\tau_{a}$ lower than the use of variable $f_{m}$, including high latitudes of North Pacific and North Atlantic during winter, Arabian Sea during summer, and Southern Oceans during summer and fall. In all other regions and seasons, the constant $f_{m}$ assumption results in higher $\tau_{a}$ up to about $45 \%$. On average, the $\tau_{a}$ derived from constant $f_{m}$ is nearly $20 \%$ higher than that derived from variable $f_{m}$.

[15] The derived anthropogenic aerosol optical depth is subject to uncertainties associated with parameters in equation (1). While rigorous validation of the MODIS-derived $\tau_{a}$ is difficult because of dearth of in situ measurements, here we provide an empirical estimate of the uncertainty associated with $\tau_{a}$. We first empirically determine uncertainties for major parameters on the basis of previous studies of satellite validations and in situ measurements [e.g., Bellouin et al., 2005; Remer et al., 2005, 2006; Smirnov et al., 2002], as listed in Table 2. Note that fine-mode fractions for individual aerosol types are derived from the MODIS observations in this study. As such the error associated with MODIS 


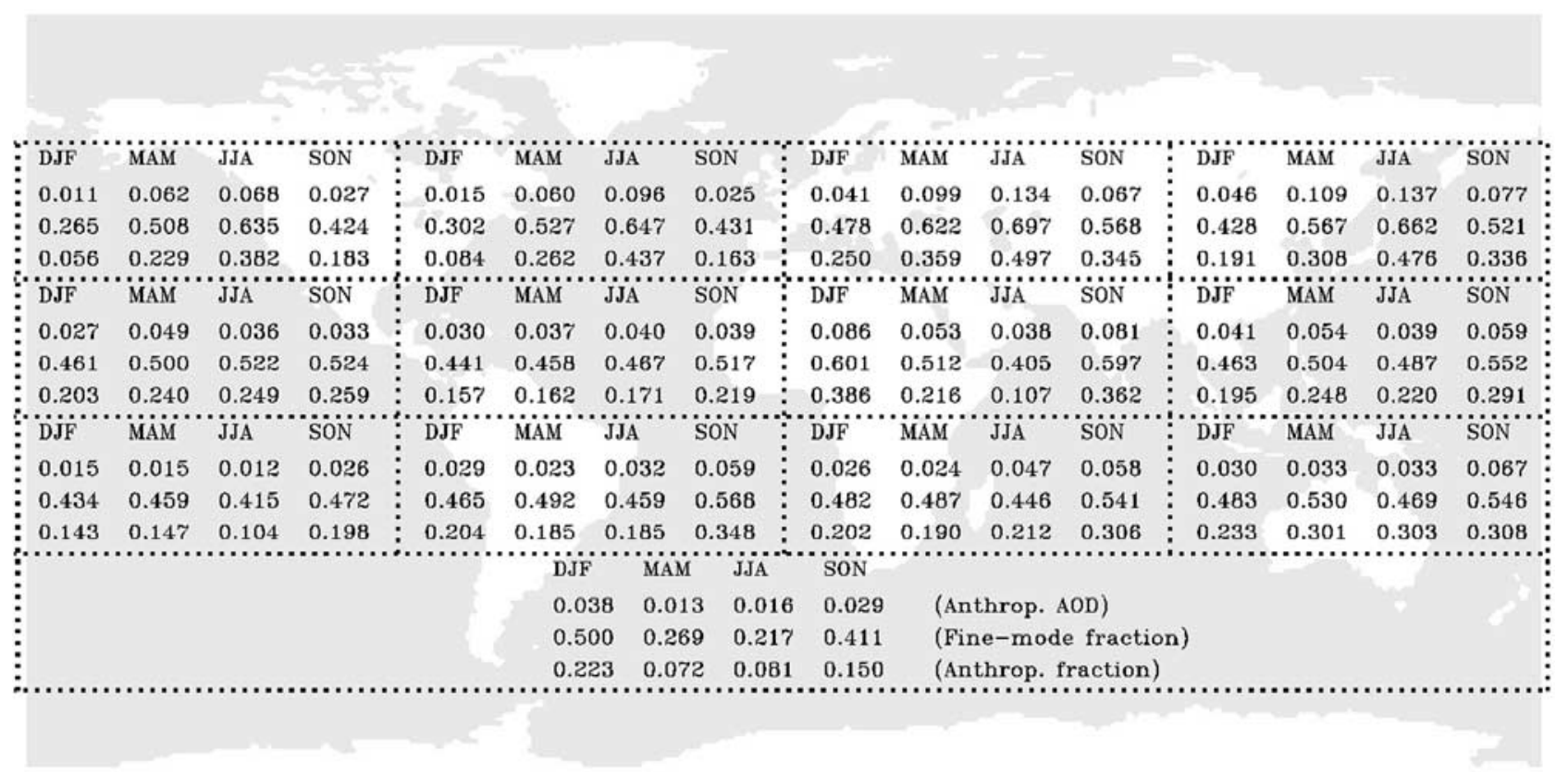

Figure 3b. Seven-year seasonal averages of anthropogenic AOD (first row within each dotted box), fine-mode fraction (second row within each dotted box), and anthropogenic fraction (third row within each dotted box), all at $550 \mathrm{~nm}$, over ocean in 13 zones (gray background).

fine-mode fraction, if not strongly dependent on aerosol type, could be largely offset by those associated with finemode fractions for individual aerosol types and hence is not included in our uncertainty analysis separately. We then apply the perturbation to each parameter accordingly while using default values for other parameters and rederive the anthropogenic AOD for the whole year of 2002. The corresponding uncertainties for $\tau_{a}$ are then calculated and listed in Table 2 by comparing the perturbations with the default. For a fractional uncertainty of $x$, the corresponding uncertainty factor (UF) is $1+x$. By assuming the probability

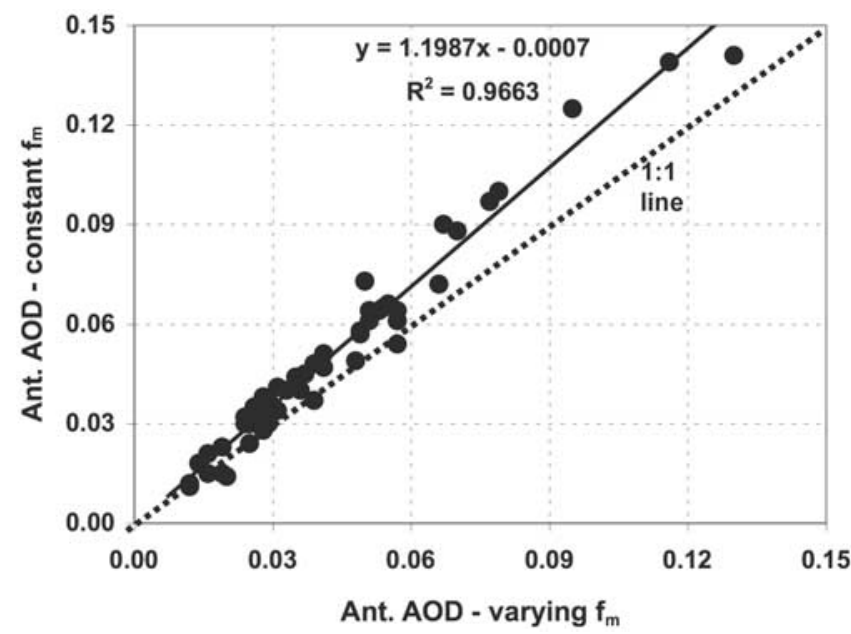

Figure 4. Comparison of the derived anthropogenic AOD at $550 \mathrm{~nm}$ using the spatially and seasonally varying marine fine-mode fraction $\left(f_{m}\right)$ with that using the constant $f_{m}$. Each of $52(=13 \times 4)$ data points represents a seasonal average over one of 13 zones defined in Figure $3 b$. distribution function for each factor is log normal and individual uncertainties are independent [Penner et al., 1994], we estimate the overall uncertainty factor of 1.52 for $\tau_{a}$ derived in this study. This suggests that the global ocean average $\tau_{a}$ ranges from 0.023 to 0.053 .

[16] Aerosols can have pronounced seasonal variations on a regional scale, as determined by emissions, chemical transormation, atmospheric transport, and removal processes. Figure 5 shows the derived 7-year (2001-2007) average seasonal cycle of anthropogenic aerosol optical depths over northern midlatitude $\left(30^{\circ} \mathrm{N}-60^{\circ} \mathrm{N}\right)$, northern tropical (equator $\left.-30^{\circ} \mathrm{N}\right)$, southern tropical $\left(30^{\circ} \mathrm{S}-\right.$ equator), and global $\left(60^{\circ} \mathrm{S}-60^{\circ} \mathrm{N}\right)$ oceans. In $30^{\circ} \mathrm{N}-60^{\circ} \mathrm{N}$ where anthropogenic aerosol is dominated by outflow of industrial and urban pollution (with some contributions from boreal forest fires in summer), the anthropogenic AOD is about 2 times larger in spring and summer than in winter and fall. Over tropical oceans (equator $-30^{\circ} \mathrm{N}$ and $30^{\circ} \mathrm{S}$-equator) where anthropogenic aerosol is dominated by biomass burning

Table 2. Estimated Uncertainties in the Derived Anthropogenic Aerosol Optical Depth at $550 \mathrm{~nm}$ Resulting From Uncertainties Associated With Individual Parameters in Equation (1) ${ }^{\mathrm{a}}$

\begin{tabular}{cccc}
\hline Parameters & $\begin{array}{c}\text { Estimated } \\
\text { Uncertainty, \% }\end{array}$ & $\begin{array}{c}\text { Resultant } \tau_{a} \\
\text { Uncertainty, \% }\end{array}$ & $\begin{array}{c}\text { Uncertainty } \\
\text { Factor (UF) for } \tau_{a}\end{array}$ \\
\hline$\tau$ & 20 & 26 & 1.26 \\
$f_{d}$ & 20 & 12 & 1.12 \\
$f_{a}$ & 20 & 27 & 1.27 \\
$f_{m}$ & 20 & 20 & 1.20 \\
$\tau_{m}$ & 50 & 15 & 1.15 \\
\hline
\end{tabular}

${ }^{a}$ Derived anthropogenic aerosol optical depth is denoted by $\tau_{a}$. The overall uncertainty is estimated by assuming that the probability distribution function for each factor is log normal and individual sources of uncertainty are independent [following Penner et al., 1994]. Total uncertainty factor for $\tau_{a}=e^{\left(\sum\left(\log U F_{i}\right)^{2}\right)^{1 / 2}}=1.52$. 


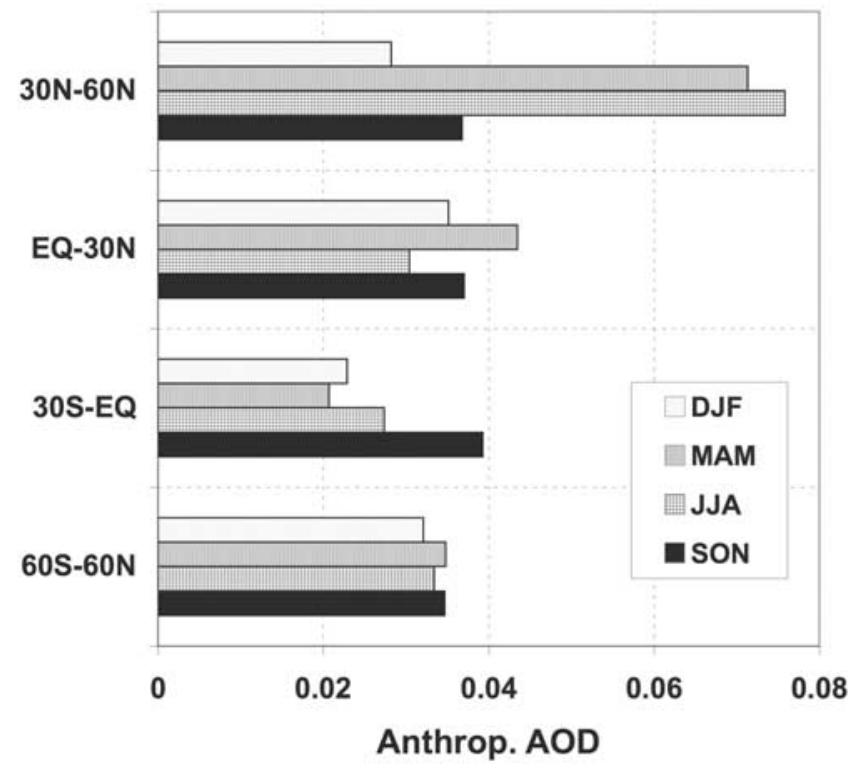

Figure 5. The 2001-2007 average seasonal cycle of MODIS-derived anthropogenic AOD at $550 \mathrm{~nm}$ over different latitude bands.

smoke, the AOD peak occurs in spring (e.g., MarchApril-May for the northern tropical oceans and SeptemberOctober-November for the southern tropical oceans). Different seasonal variations of AOD in different latitude bands offset each other, resulting in no clear seasonal variation on a global ocean basis.

[17] Figure 6 shows interannual variations of seasonal average anthropogenic aerosol optical depth over the 7-year period in individual regions corresponding to the divisions used in Figure 5. Given that large seasonal variations could mask any potential tendency of changes over the period, the anthropogenic AOD in Figure 6 has been deseasonalized using the 7-year average seasonal cycle as shown in Figure 5. A linear regression is performed for the variation of average anthropogenic AOD with time, shown as solid line in Figure 6 along with calculated regression equation and correlation coefficient $\left(R^{2}\right)$. In the northern midlatitudes (Figure 6a), there was a much elevated value of anthropogenic AOD in spring 2003, and a relatively small elevation in summer 2003, corresponding to record intense Siberian forest fires [Goldammer et al., 2004; Wotawa et al., 2006]. Statistical analysis suggests no clear tendency of AOD change over the period (correlation as low as 0.05). A further examination of two subregions in the northern midlatitudes, namely the northwestern Pacific $\left(30^{\circ} \mathrm{N}-60^{\circ} \mathrm{N}, 115^{\circ} \mathrm{E}-\right.$ $\left.180^{\circ} \mathrm{E}\right)$ and North Atlantic $\left(30^{\circ} \mathrm{N}-60^{\circ} \mathrm{N}, 70^{\circ} \mathrm{W}-20^{\circ} \mathrm{E}\right)$, does not yield higher correlations or clearer tendencies of change. On the contrary, the anthropogenic AOD shows a statistically significant (i.e., $R^{2}$ of $\sim 0.4$ ), increasing tendency over the 7 -year period in the tropical oceans (Figures $6 \mathrm{~b}$ and $6 \mathrm{c}$ ). In equator $-30^{\circ} \mathrm{N}$ latitudes, $\tau_{a}$ increases at a rate of $0.0005 \tau /$ season (or $0.002 \tau / \mathrm{a}$ ). In $30^{\circ} \mathrm{S}$-equator latitudes, the increasing rate of $\tau_{a}$ is $0.0003 \tau /$ season (or $0.0012 \tau / \mathrm{a}$ ), which is roughly half of its northern counterpart. On a global ocean average (Figure $6 \mathrm{~d}$ ), $\tau_{a}$ shows an increasing tendency at a rate of $0.0012 \tau / \mathrm{a}$, but with a smaller correlation of $R^{2}=$ 0.27 . The above analysis may suggest that biomass burning emissions and fossil fuel consumptions in tropical regions may have been increasing during 2001-2007. On the other hand, some other factors such as the sensor calibration and retrieval uncertainty may also contribute to the change, and future efforts are needed to quantify them. The data record from MODIS is also too short to derive long-term trends of aerosols.

[18] How well does the derived anthropogenic aerosol optical depth compare with other measurement-based estimates and model simulations? Bellouin et al. [2005] use prescribed, in situ measurement-based thresholds of finemode fraction $f(f>0.83$ for pollution-dominated aerosol, $f<0.35$ for dust and sea salt mixture, and in between for
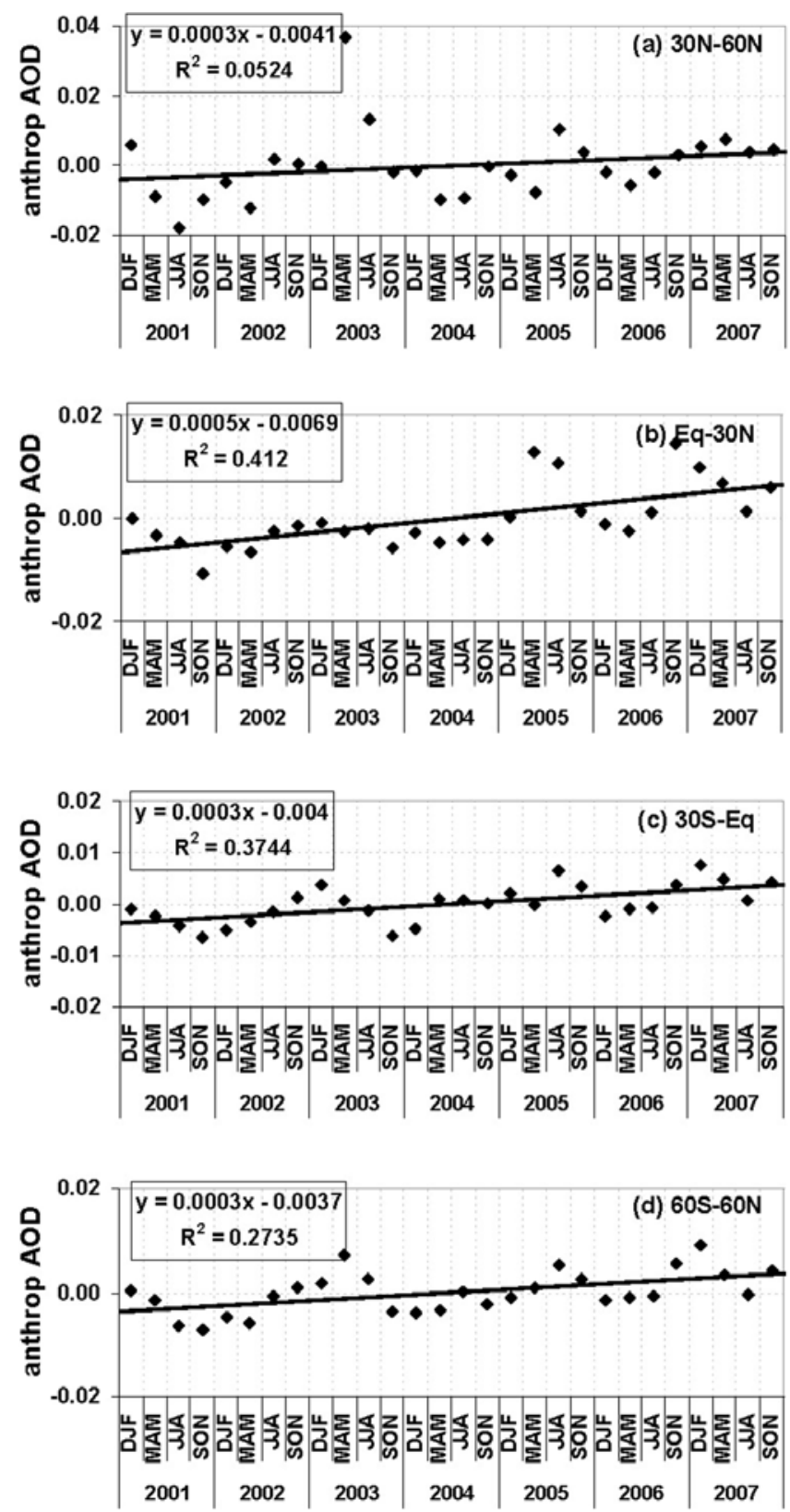

Figure 6. Variations of deseasonalized anthropogenic AOD at $550 \mathrm{~nm}$ over the 7-year period in different regions. A linear regression is performed, shown as a solid line, along with regression equation and correlation coefficient. 
(a) This study

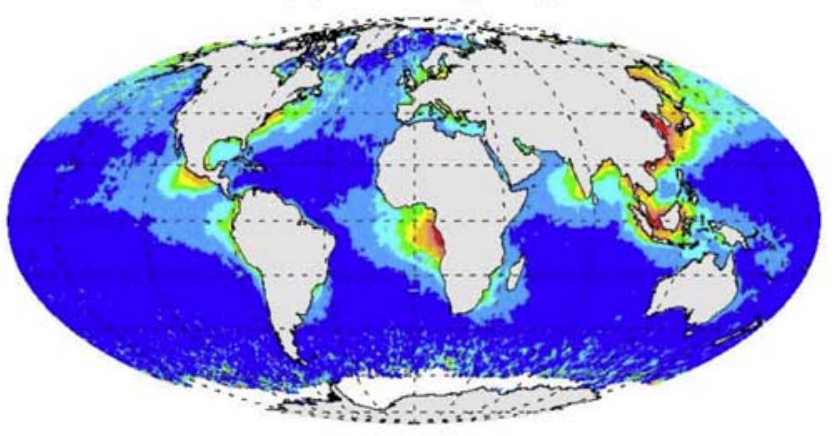

(b) B08

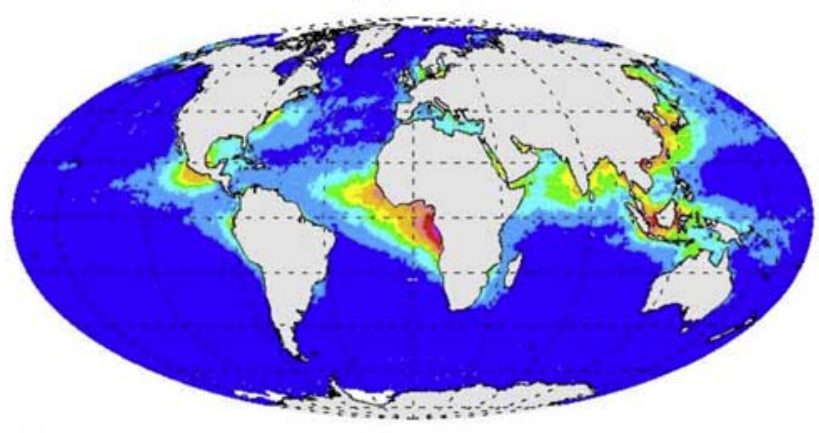

(c) GOCART
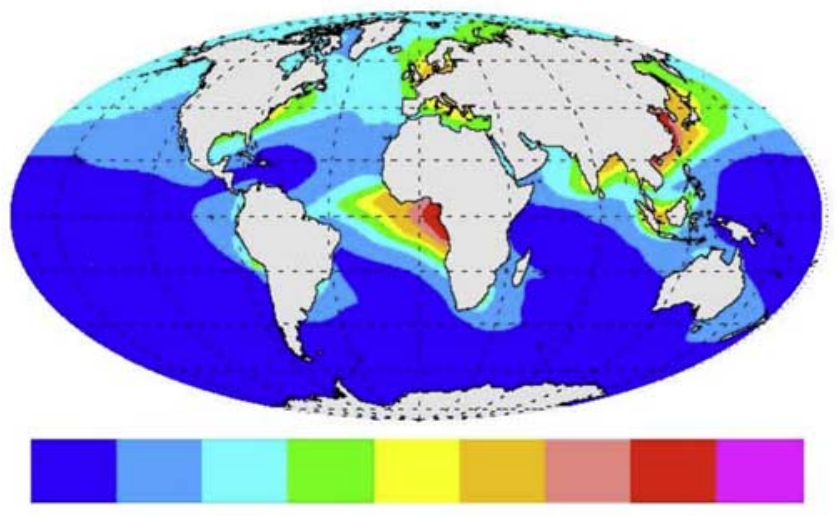

$\begin{array}{llllllllll}0.0 & 0.02 & 0.04 & 0.06 & 0.08 & 0.10 & 0.15 & 0.2 & 0.3 & 0.5\end{array}$

Figure 7. Comparison of 2002 annual average anthropogenic AOD at $550 \mathrm{~nm}$ over ocean derived in (a) this study and (b) B08, both from Terra MODIS Collection 5 data, and from (c) GOCART simulations.

pollution, dust, and sea salt mixture) aided by the Total Ozone Mapping Spectroradiometer (TOMS) absorbing aerosol index (AAI) to separate anthropogenic aerosol from mineral dust and sea salt. Background sea salt AOD is subtracted by using an empirical AOD dependence on surface wind speed. The method was originally applied to MODIS C4 [Bellouin et al., 2005] and most recently to MODIS C5 measurements for updated estimates of the anthropogenic aerosol optical depth and direct radiative forcing [Bellouin et al., 2008] (hereafter referred to as B08). Although B08 use the same MODIS C5 measurements as this study does, the two studies use different criteria and approach to separate anthropogenic aerosol from dust and marine aerosol. Figure 7 compares the annual average anthropogenic aerosol optical depth over oceans derived in this study (Figure 7a) with that from B08 (Figure 7b). While the two approaches give similar spatial patterns, some major differences do exist on regional scales. On one hand, off the coast of North Africa the anthropogenic outflow derived in this study is smaller in magnitude and less extensive in space than that from B08. The annual average $\tau_{a}$ over $0^{\circ}-20^{\circ} \mathrm{N}$ and $40^{\circ} \mathrm{W}-10^{\circ} \mathrm{E}$ is 0.034 from this study, which is a factor of 2-3 smaller than 0.087 from B08. On the other hand, B08 derive weaker pollution outflows over North Pacific and North Atlantic than this study does. The relatively large $\tau_{a}$ over Southern Ocean as shown in Figure 7 a would be an artifact resulting from the relatively poor quality of MODIS retrievals and our simplified representation of marine AOD in such regimes with strong winds and high fractions of cloud [Zhang et al., 2005; Smirnov et al., 2006]. On annual and global (again averaged only over where measurements are available) basis, the average $\tau_{a}$ is estimated to be 0.032 in this study, which is substantially larger than 0.021 of B08. When the estimated uncertainty factor of 1.52 discussed earlier is applied to our estimate, the B08 estimate is consistent with the low bound of anthropogenic AOD of this study.

[19] A number of factors should contribute to such differences. For example, it is likely that B08 may have missed some pollution outflow far from coastal regions (e.g., North Atlantic and North Pacific) when the pollution contribution is not large enough to elevate the MODIS fine-mode fraction to the prescribed high threshold (i.e., 0.83) for anthropogenic aerosol. The use of TOMS absorbing aerosol index would not help in these cases for separating pollution from dust and sea salt, because of weak sensitivity of TOMS to these pollution plumes at relatively low altitude and with weak ultraviolet (UV) absorption. The examined large difference off the coast of North Africa influenced by both dust and smoke may manifest the difficulty in separating smoke from dust from space. Given that B08 use a lower $f$ value as a threshold of for categorizing "pure" smoke or pollution than we are using, their smoke AOD would be larger than that from this study. For a smoke-dust mixture (i.e., $0.35<f<$ 0.83 ), smoke is separated from dust by using $f$ as an approximation for the fraction of smoke in B08. Inherent in this approximation is that fine-mode aerosol comes exclusively from smoke, which could overestimate the smoke AOD because a fine-mode fraction of dust is not negligible. These differences in algorithms of separating smoke from dust are thus likely to result in smaller and less extensive smoke outflow from North Africa in this study than is found by B08. As an exercise we rederive the anthropogenic AOD by using the thresholds recommended by B08 for $f_{a}(=0.83)$ and $f_{d}(=0.35)$ and also reducing the $f_{m}$ by half. This yields an average anthropogenic AOD of 0.073 over $0^{\circ}-20^{\circ} \mathrm{N}$ and $40^{\circ} \mathrm{W}-10^{\circ} \mathrm{E}$, much closer to 0.087 from B08. However, the global average anthropogenic AOD using these modified parameters would increase by about $70 \%$ to 0.058 , resulting in much larger discrepancies against 0.021 of B08. This exercise suggests the complexity of separating anthropogenic aerosol from natural one. There is a need to examine potential temporal and spatial variations of fine-mode fraction for pollution and dust. In situ measurements, presumably 
more accurate than the satellite-based estimates (e.g., Table 1), should be collected to facilitate understanding of uncertainties associated with satellite measurements and hence developing a strategy of integrating in situ and satellite measurements without introducing additional uncertainties resulting from possible discrepancies between the two measurements.

[20] Our estimated ocean average anthropogenic AOD is also about $50 \%$ larger than 0.021 from an ensemble of seven model simulations from the Aerosol Comparison between Observations and Models (AeroCom) group [Schulz et al., 2006]. Such differences can be at least partially attributed to different definitions used in the two studies. While anthropogenic aerosol is defined as a difference between presentday and pre-industrial simulations by Schulz et al. [2006], it is defined in the satellite-based studies as a difference between present-day total aerosol and natural aerosol with an assumption that biomass burning aerosol is completely man made. Given that part of biomass burning aerosol is of natural origin and should have occurred in pre-industrial era, the value from Schulz et al. [2006] should be reasonably smaller than the satellite-based estimates. An adequate assessment of such difference in the definition of anthropogenic aerosol is needed to get a quantitative understanding of the apparent discrepancies in current estimates of anthropogenic aerosol optical depth [Bellouin et al., 2008].

[21] Here we compare the MODIS-based anthropogenic AOD with GOCART simulations using the similar definition of anthropogenic aerosol, i.e., a difference between present-day total aerosol and present-day natural aerosol. The GOCART model was run twice, once with all aerosol sources and then without anthropogenic and biomass burning sources. A difference between the two runs is used to represent anthropogenic aerosol, as shown in Figure 7c. Here we have assumed that biomass burning aerosols are completely man-made, which is also somewhat consistent with the assumption made for the satellite-based estimates. In general, GOCART simulations show higher $\tau_{a}$ than both satellite-based approaches in most regions. On a global average, the average of 0.030 from GOCART simulations is consistent with the estimate from this study to about $10 \%$, but is about $50 \%$ higher than those of B08 and Schulz et al. [2006]. On regional scales, the model-satellite difference depends on the method of satellite-based estimates. On one hand, off the coast of North Africa $\left(0^{\circ}-20^{\circ} \mathrm{N}, 40^{\circ} \mathrm{W}-10^{\circ} \mathrm{E}\right)$ the GOCART simulations give an average of 0.093 for the anthropogenic AOD, which is close to that of B08 but is nearly a factor of 3 larger than this study. On the other hand, the model simulations of pollution outflow over North Pacific and North Atlantic are consistent with this study, but much stronger than those of B08.

\section{Concluding Remarks}

[22] Marine aerosol fine-mode fraction is determined by a number of factors associated with the state of atmosphere and ocean. In this study, we have derived empirically the fine-mode fraction for background marine aerosol, $f_{m}$, from the MODIS Collection 5 over-ocean measurements. This MODIS-based $f_{m}$ shows large seasonal and geographical variations that are generally consistent with GOCART and
GMI simulations of marine aerosol. The seasonally and spatially varying $f_{m}$ has been implemented into the method of deriving anthropogenic AOD from MODIS observations [Kaufman et al., 2005a]. It is found that a use of constant $f_{m}$ as done in previous studies [Kaufman et al., 2005a, 2005 b] would have overestimated the anthropogenic AOD over global ocean by nearly $20 \%$, with the overestimate up to $\sim 45 \%$ for some regions and seasons. It is estimated that the 7-year (2001-2007) global (where MODIS measurements are available) ocean average anthropogenic AOD $\left(\tau_{a}\right)$ is 0.035 , which is consistent with GOCART simulation but about $50 \%$ larger than the satellite-based estimate by Bellouin et al. [2008]. The derived 7-year anthropogenic AOD over tropical oceans (dominated by biomass burning smoke) shows a tendency of increase at a rate of 0.002 (northern tropical ocean) and 0.001 (southern tropical ocean) $\tau_{a}$ /a from 2001 to 2007. In Northern Hemisphere midlatitudes dominated by industrial and urban pollution, there is no statistically significant tendency of increase or decrease.

[23] As discussed earlier in this study, current methods of deriving anthropogenic aerosol component have used exclusively the MODIS aerosol data with differences in specifics of the approaches and the derived global ocean anthropogenic AOD can still differ by about 50\%. Estimating the anthropogenic aerosol component over land is even more difficult because of larger uncertainties in aerosol retrievals than over ocean. The aerosol forcing efficiency, defined as aerosol direct forcing per unit of $\tau_{a}$ and a useful quantity for calculating the aerosol direct forcing, is mainly governed by aerosol size distribution and chemical composition (determining the aerosol single-scattering albedo and phase function), surface reflectivity, and solar geometry [Zhou et al., 2005]. Current estimates of global ocean average anthropogenic aerosol forcing efficiency also differ substantially, ranging from nearly $-30 \mathrm{~W} \mathrm{~m}^{-2} \tau_{a}^{-1}$ to greater than $-40 \mathrm{~W} \mathrm{~m}^{-2} \tau_{a}^{-1}$ [Bellouin et al., 2005; Christopher et al., 2006; Kaufman et al., 2005a; Quaas et al., 2008; Remer and Kaufman, 2006; Schulz et al., 2006; Yu et al., 2004, 2006; Zhao et al., 2008]. On regional scales, uncertainty ranges for $\tau_{a}$ and forcing efficiency can be much larger than the global averages. To narrow down the uncertainty range, substantial effort is required in the future. It will be helpful to evaluate the MODIS-based estimates by developing independent approaches using data sets from other satellite sensors, for example, measurements of particle shape and size from the Multiangle Imaging SpectroRadiometer (MISR) [Kahn et al., 2001] and the Cloud-Aerosol Lidar and Infrared Pathfinder Satellite Observations (CALIPSO) [Winker et al., 2007]. Future satellite measurements should focus on improved retrievals of such aerosol properties as size distribution, particle shape, and absorption, along with algorithm refinement for better AOD retrievals. It is also strategically needed to conduct in situ measurements that allow for the characterization of anthropogenic AOD or anthropogenic fraction in context of evaluating or validating satellite remote sensing measurements of the atmospheric column. Finally, the better determination of anthropogenic aerosols also requires a quantification of biomass burning ignited by lightning (natural origin) and mineral dust due to human-induced changes of land cover/land use and climate (anthropogenic origin). 
[24] Acknowledgments. The work by researchers associated with NASA was supported by NASA's Atmospheric Composition Modeling and Analysis Program, and Radiation Sciences Program. The work by N.B. was supported by the joint UK Department for Environment, Food and Rural Affairs and Ministry of Defense Integrated Climate Programme GA01101, CBC/2B/0417 Annex C5. We thank three reviewers for their helpful comments

\section{References}

Anderson, T. L., Y. Wu, D. A. Chu, B. Schmid, J. Redemann, and O. Dubovik (2005a), Testing the MODIS satellite retrieval of aerosol fine-mode fraction, J. Geophys. Res., 110, D18204, doi:10.1029/2005JD005978.

Anderson, T. L., et al. (2005b), A-Train strategy for quantifying direct climate forcing by anthropogenic aerosols, Bull. Am. Meteorol. Soc., 86, 1795-1809, doi:10.1175/BAMS-86-12-1795.

Bates, T. S., P. K. Quinn, D. J. Coffman, J. E. Johnson, T. L. Miller, D. S. Covert, A. Wiedensohler, S. Leinert, A. Nowak, and C. Neusüss (2001), Regional physical and chemical properties of the marine boundary layer aerosol across the Atlantic during Aerosols99: An overview, J. Geophys. Res., 106(D18), 20,767-20,782, doi:10.1029/2000JD900578.

Bates, T. S., et al. (2006), Aerosol direct radiative effects over the northwest Atlantic, northwest Pacific, and North Indian Oceans: Estimates based on in-situ chemical and optical measurements and chemical transport modeling, Atmos. Chem. Phys., 6, 1657-1732.

Bellouin, N., O. Boucher, J. Haywood, and M. S. Reddy (2005), Global estimate of aerosol direct radiative forcing from satellite measurements, Nature, 438, 1138-1141, doi:10.1038/nature04348.

Bellouin, N., A. Jones, J. Haywood, and S. A. Christopher (2008), Updated estimate of aerosol direct radiative forcing from satellite observations and comparison against the Hadley Centre climate model, J. Geophys. Res., 113, D10205, doi:10.1029/2007JD009385.

Bian, H., M. Chin, J. Rodriguez, H. Yu, J. E. Penner, and S. Strahan (2009), Sensitivity of aerosol optical thickness and aerosol direct radiative effect to relative humidity, Atmos. Chem. Phys., 9, 2375-2386.

Chin, M., R. B. Rood, S.-J. Lin, J. F. Muller, and A. M. Thompson (2000a), Atmospheric sulfur cycle in the global model GOCART: Model description and global properties, J. Geophys. Res., 105(D20), 24,671-24,687, doi:10.1029/2000JD900384.

Chin, M., D. L. Savoie, B. J. Huebert, A. R. Bandy, D. C. Thornton, T. S Bates, P. K. Quinn, E. S. Saltzman, and W. J. De Bruyn (2000b), Atmospheric sulfur cycle in the global model GOCART: Comparison with field observations and regional budgets, J. Geophys. Res., 105(D20), 24,689_ 24,712, doi:10.1029/2000JD900385.

Chin, M., P. Ginoux, S. Kinne, O. Torres, B. Holben, B. Duncan, R. Martin, J. Logan, A. Higurashi, and T. Nakajima (2002), Tropospheric aerosol optical thickness from the GOCART model and comparisons with satellite and sunphotometer measurements, J. Atmos. Sci., 59, 461-483, doi:10.1175/1520-0469(2002)059<0461:TAOTFT >2.0.CO;2.

Christopher, S. A., J. Zhang, Y. J. Kaufman, and L. A. Remer (2006), Satellite-based assessment of top of atmosphere anthropogenic aerosol radiative forcing over cloud-free oceans, Geophys. Res. Lett., 33, L15816, doi:10.1029/2005GL025535.

Goldammer, J. G., A. Sukhinin, and I. Csiszar (2004), The current fire situation in the Russian Federation: Implications for enhancing international and regional cooperation in the UN framework and the global programs on fire monitoring and assessment, Int. For. Fire News, 29, $89-111$

Haywood, J., and M. Schulz (2007), Causes of the reduction in uncertainty in the anthropogenic radiative forcing of climate between IPCC (2001) and IPCC (2007), Geophys. Res. Lett., 34, L20701, doi:10.1029/ 2007GL030749.

Higurashi, A., and T. Nakajima (2002), Detection of aerosol types over the East China Sea near Japan from four-channel satellite data, Geophys. Res. Lett., 29(17), 1836, doi:10.1029/2002GL015357.

Jones, T. A., and S. A. Christopher (2007), MODIS derived fine mode fraction characteristics of marine, dust, and anthropogenic aerosols over the ocean, constrained by GOCART, MOPITT, and TOMS, J. Geophys. Res., 112, D22204, doi:10.1029/2007JD008974.

Kahn, R., P. Banerjee, and D. McDonald (2001), The sensitivity of multiangle imaging to natural mixtures of aerosols over ocean, $J$. Geophys. Res., 106(D16), 18,219-18,238, doi:10.1029/2000JD900497.

Kaufman, Y., A. Smirnov, B. Holben, and O. Dubovik (2001), Baseline maritime aerosol: Methodology to derive the optical thickness and scattering properties, Geophys. Res. Lett., 28(17), 3251-3254.

Kaufman, Y. J., D. Tanré, and O. Boucher (2002), A satellite view of aerosols in the climate system: Review, Nature, 419, 215-223, doi:10.1038/nature01091.

Kaufman, Y. J., O. Boucher, D. Tanré, M. Chin, L. A. Remer, and T. Takemura (2005a), Aerosol anthropogenic component estimated from satellite data, Geophys. Res. Lett., 32, L17804, doi:10.1029/ 2005GL023125

Kaufman, Y. J., I. Koren, L. A. Remer, D. Tanré, P. Ginoux, and S. Fan (2005b), Dust transport and deposition observed from the Terra-Moderate Resolution Imaging Spectroradiometer (MODIS) spacecraft over the Atlantic Ocean, J. Geophys. Res., 110, D10S12, doi:10.1029/ 2003JD004436.

Kleidman, R. G., N. T. O'Neill, L. A. Remer, Y. J. Kaufman, T. F. Eck, D. Tanré, O. Dubovik, and B. N. Holben (2005), Comparison of Moderate Resolution Imaging Spectroradiometer (MODIS) and Aerosol Robotic Network (AERONET) remote-sensing retrievals of aerosol fine mode fraction over ocean, J. Geophys. Res., 110, D22205, doi:10.1029/ 2005JD005760.

Leck, C., and E. K. Bigg (2005), Source and evolution of the marine aerosol-A new perspective, Geophys. Res. Lett., 32, L19803, doi:10.1029/2005GL023651.

Levy, R., L. A. Remer, S. Mattoo, E. Vermote, and Y. Kaufman (2007), Second-generation algorithm for retrieving aerosol properties over land from MODIS spectral reflectance, J. Geophys. Res., 112, D13211, doi:10.1029/2006JD007811.

Liss, P. S. (2007), Trace gas emissions from the marine biosphere, Philos. Trans. R. Soc., Ser. A., 365, 1697-1704, doi:10.1098/rsta.2007.2039.

O'Dowd, C. D., M. C. Facchini, F. Cavalli, D. Ceburnis, M. Mircea, S. Decesari, S. Fuzzi, Y. J. Yoon, and J. P. Putaud (2004), Biogenically driven organic contribution to marine aerosol, Nature, 431, 676-680, doi:10.1038/nature02959.

Penner, J. E., R. J. Charlson, J. M. Hales, N. S. Laulainen, R. Leifer, T. Novakov, J. Ogren, L. F. Radke, S. E. Schwartz, and L. Travis (1994), Quantifying and minimizing uncertainty of climate forcing by anthropogenic aerosols, Bull. Am. Meteorol. Soc., 75, 375-400, doi:10.1175 1520-0477(1994)075<0375:QAMUOC >2.0.CO;2.

Quaas, J., O. Boucher, N. Bellouin, and S. Kinne (2008), Satellite-based estimate of the direct and indirect aerosol climate forcing, J. Geophys. Res., 113, D05204, doi:10.1029/2007JD008962.

Remer, L. A., and Y. J. Kaufman (2006), Aerosol direct radiative effect at the top of the atmosphere over cloud free ocean derived from four years of MODIS data, Atmos. Chem. Phys., 6, 237-253.

Remer, L. A., et al. (2005), The MODIS aerosol algorithm, products, and validation, J. Atmos. Sci., 62, 947-973, doi:10.1175/JAS3385.1.

Remer, L. A., D. Tanré, Y. J. Kaufman, R. C. Levy, and S. Mattoo (2006), Algorithm for remote sensing of tropospheric aerosol from MODIS: Collection 005, in ATBD-MOD-96, 88 pp., NASA Goddard Space Flight Cent., Greenbelt, Md. (Available at http://modis-atmos.gsfc.nasa. gov/reference_atbd.php)

Remer, L. A., et al. (2008), An emerging aerosol climatology from the MODIS satellite sensors, J. Geophys. Res., 113, D14S07, doi:10.1029/ 2007JD009661.

Rudich, Y., Y. J. Kaufman, U. Dayan, H. Yu, and R. G. Kleidman (2008), Estimation of transboundary transport of pollution aerosols by remote sensing in the eastern Mediterranean, J. Geophys. Res., 113, D14S13, doi:10.1029/2007JD009601.

Schulz, M., et al. (2006), Radiative forcing by aerosols as derived from the AeroCom present-day and pre-industrial simulations, Atmos. Chem. Phys., 6, 5225-5246.

Shinozuka, Y., A. D. Clarke, S. G. Howell, V. N. Kapustin, and B. J. Huebert (2004), Sea-salt vertical profiles over the Southern and tropical Pacific oceans: Microphysics, optical properties, spatial variability, and variations with wind speed, J. Geophys. Res., 109, D24201, doi:10.1029/ 2004JD004975.

Smirnov, A., B. N. Holben, Y. J. Kaufman, O. Dubovik, T. F. Eck, I. Slutsker, C. Pietras, and R. N. Halthore (2002), Optical properties of atmospheric aerosol in maritime environments, J. Atmos. Sci., 59, 501-523, doi:10.1175/1520-0469(2002)059<0501:OPOAAI $>2.0$.CO;2.

Smirnov, A., et al. (2006), Ship-based aerosol optical depth measurements in the Atlantic Ocean: Comparison with satellite retrievals and GOCART model, Geophys. Res. Lett., 33, L14817, doi:10.1029/2006GL026051.

Tanré, D., Y. J. Kaufman, M. Herman, and S. Mattoo (1997), Remote sensing of aerosol properties over oceans using the MODIS/EOS spectral radiances, J. Geophys. Res., 102(D14), 16,971-16,988, doi:10.1029/ 96JD03437.

Tanré, D., F. M. Bréon, J. L. Deuzé, M. Herman, P. Goloub, F. Nadal, and A. Marchand (2001), Global observation of anthropogenic aerosols from satellite, Geophys. Res. Lett., 28(24), 4555-4558, doi:10.1029/ 2001GL013036.

Wilson, S. R., and B. W. Forgan (2002), Aerosol optical depth at Cape Grim, Tasmania, 1986-1999, J. Geophys. Res., 107(D8), 4068, doi:10.1029/2001JD000398.

Winker, D. M., W. H. Hunt, and M. J. McGill (2007), Initial performance assessment of CALIOP, Geophys. Res. Lett., 34, L19803, doi:10.1029/ 2007GL030135. 
Wotawa, G., L.-E. De Geer, A. Bekcer, R. D’Amours, M. Jean, R. Servranckx, and $\mathrm{K}$. Ungar (2006), Inter- and intra-continental transport of radioactive cesium released by boreal forest fires, Geophys. Res. Lett., 33, L12806, doi:10.1029/2006GL026206.

Yu, H., R. E. Dickinson, M. Chin, Y. J. Kaufman, M. Zhou, L. Zhou, Y. Tian, O. Dubovik, and B. N. Holben (2004), The direct radiative effect of aerosols as determined from a combination of MODIS retrievals and GOCART simulations, J. Geophys. Res., 109, D03206, doi:10.1029/2003JD003914.

Yu, H., et al. (2006), A review of measurement-based assessments of the aerosol direct radiative effect and forcing, Atmos. Chem. Phys., 6, 613666.

Yu, H., L. A. Remer, M. Chin, H. Bian, R. G. Kleidman, and T. Diehl (2008), A satellite-based assessment of trans-pacific transport of pollution aerosol, J. Geophys. Res., 113, D14S12, doi:10.1029/2007JD009349.

Zhang, J., J. S. Reid, and B. N. Holben (2005), An analysis of potential cloud artifacts in MODIS over ocean aerosol optical thickness products, Geophys. Res. Lett., 32, L15803, doi:10.1029/2005GL023254.
Zhao, T. X.-P., H. Yu, I. Laszlo, M. Chin, and W. C. Conant (2008), Derivation of component aerosol direct radiative forcing at the top of atmosphere for clear-sky oceans, J. Quant. Spectrosc. Radiat. Transfer, 109(7), 1162-1186, doi:10.1016/j.jqsrt.2007.10.006.

Zhou, M., H. Yu, R. E. Dickinson, O. Dubovik, and B. N. Holben (2005), A normalized description of the direct effect of key aerosol types on solar radiation as estimated from AERONET aerosols and MODIS albedos, J. Geophys. Res., 110, D19202, doi:10.1029/2005JD005909.

N. Bellouin, Met Office, Hadley Centre, FitzRoy Road, Exeter, Devon EX1 3PB, UK.

H. Bian, M. Chin, T. Diehl, R. G. Kleidman, L. A. Remer, and H. Yu, Laboratory for Atmospheres, NASA Goddard Space Flight Center, Code 613.2, Greenbelt, MD 20771, USA. (Hongbin.Yu@nasa.gov) 